\title{
A Precipitation Phenomenon of Titanium Compounds in Aluminum Melts and the Refinement Fading Mechanism of the Al-5Ti-0.62C Master Alloy
}

\author{
Wanwu Ding, ${ }^{1,2}$ Wenjun Zhao, ${ }^{1,2}$ and Tiandong Xia ${ }^{1,2}$ \\ ${ }^{1}$ School of Materials Science and Engineering, Lanzhou University of Technology, Lanzhou, Gansu 730050, China \\ ${ }^{2}$ State Key Laboratory of Gansu Advanced Non-Ferrous Metal Materials, Lanzhou, Gansu 730050, China \\ Correspondence should be addressed to Tiandong Xia; xiatid@sina.com
}

Received 20 August 2014; Revised 31 December 2014; Accepted 2 January 2015

Academic Editor: Jie Dai

Copyright ( $\odot 2015$ Wanwu Ding et al. This is an open access article distributed under the Creative Commons Attribution License, which permits unrestricted use, distribution, and reproduction in any medium, provided the original work is properly cited.

The Al-5Ti-0.62C master alloy was prepared through a method of thermal explosion in molten aluminum. The process of remelting and refining of commercially pure aluminum was conducted, and precipitation samples with different heat-treatment times were obtained. Scanning electron microscopy (SEM), X-ray diffraction (XRD), optical microscopy (OM), and other techniques were used to analyze the microstructure of the precipitates at the bottom of the samples so as to explore the fading mechanism of Al-Ti$\mathrm{C}$ alloy refinement. The results showed that an obvious precipitation phenomenon of titanium compounds existed in the remelted Al-5Ti-0.62 $\mathrm{C}$ master alloy and that there were both $\mathrm{TiC}$ compounds and $\mathrm{TiAl}_{3}$ compounds in the precipitates; in the refined pure aluminum samples, the precipitates were mainly TiC compounds. Precipitation of titanium compounds in aluminum melting is the main cause of fading in the refinement effect of an Al-Ti-C master alloy.

\section{Introduction}

With their good grain refining effect, aluminum alloy grain refiners are widely used during the process of melting and casting of aluminum and its alloys [1]. Currently, the most frequently used are grain refiners of the Al-Ti-B series [2]. However, during their use, it is found that $\mathrm{TiB}_{2}$ particles are easily aggregated and precipitated and even show a so-called poisoning phenomenon of grain refiners in the melting and casting process, severely reducing the grain refinement effect of grain refiners and resulting in coarse grains that will affect the subsequent related performances of the casting ingots [3-5]. In recent years, Al-Ti-C grain refiners have received increasing attention. Studies have shown that in some cases [6], Al-Ti-C exhibits a better refining effect than Al-Ti-B does, and the wide variety of sources of $C$ can help achieve greener production [7]. The Al-Ti-C master alloy is considered to be a grain refiner that has good applicability and is the most studied [8-11]. The relationships among preparative technology, microstructure of the Al-Ti-C master alloy, and its refining effect, as well as their collective refinement and poisoning mechanisms, have been studied both at home and abroad [1214]. As investigators continue to deepen their understanding of the grain refinement phenomenon, they have proposed many theories [15] aimed at grain refinement mechanisms, but there have been to the present time no unified views offered. Grain refinement mechanisms of aluminum and aluminum alloys are very complex, so it is still very difficult to fully resolve their refinement processes and mechanisms. In the present study we aimed to conduct an in-depth analysis of mechanisms of refinement fading of the Al-Ti-C alloy through the analysis of the precipitation phenomenon in the remelting process of the Al-5Ti-0.62C master alloy and the process of refining of commercially pure aluminum; this will provide clarification of the preparation and application and refinement of the fading mechanism of Al-Ti-C alloys.

\section{Experimental Materials and Methods}

The primary materials used in the experiments included $\mathrm{Al}$ powder (99.6\%), Ti powder (99.3\%), C powder (99.8\%), and commercially pure aluminum. The supplier, particle size of 
TABLE 1: Characteristics of materials.

\begin{tabular}{|c|c|c|c|}
\hline Materials & Supplier & Grain size $/ \mu \mathrm{m}$ & Purity $/ \%$ \\
\hline Al powder & $\begin{array}{l}\text { The Northwest } \\
\text { Aluminum Company }\end{array}$ & $61-74$ & 99.6 \\
\hline Ti powder & $\begin{array}{l}\text { Shangxi Baoji state } \\
\text { Construction } \\
\text { Pioneer Metals } \\
\text { Corporation }\end{array}$ & $38-44$ & 99.3 \\
\hline C powder & $\begin{array}{l}\text { Qingdao Huatai } \\
\text { Lubricate Pressurize } \\
\text { Science \& Technology } \\
\text { Co. Ltd. }\end{array}$ & $11-30$ & 99.8 \\
\hline $\begin{array}{l}\text { Commercially } \\
\text { pure } \mathrm{Al}\end{array}$ & $\begin{array}{l}\text { The Northwest } \\
\text { Aluminum Company }\end{array}$ & - & 99.7 \\
\hline
\end{tabular}

TABLE 2: EDS composition analysis of point $\mathrm{A}$ and point $\mathrm{B}$ in Figure 2 .

\begin{tabular}{lccc}
\hline Point number & $x(\mathrm{Al}) / \%$ & $x(\mathrm{Ti}) / \%$ & $x(\mathrm{C}) / \%$ \\
\hline A & 69.72 & 21.85 & 8.43 \\
B & 46.50 & 25.52 & 27.98 \\
\hline
\end{tabular}

the powders, and purity are given in Table 1 . The main raw materials were made through ball mixing and cold pressing into prefabricated blocks. The molar ratio of the composition of prefabricated blocks containing $\mathrm{Al}, \mathrm{Ti}$, and $\mathrm{C}$ powders was $5: 2: 1$. The prefabricated blocks went through a thermal explosion reaction in pure molten aluminum at a temperature of $780^{\circ} \mathrm{C}[16,17]$.

The same quality Al-5Ti-0.62 $\mathrm{C}$ master alloy was placed in an $\mathrm{Al}_{2} \mathrm{O}_{3}$ crucible for heating and melting. At a temperature of $730^{\circ} \mathrm{C}$, the $\mathrm{Al}-5 \mathrm{Ti}-0.62 \mathrm{C}$ alloy melted and was preserved for $30 \mathrm{~min}, 60 \mathrm{~min}, 120 \mathrm{~min}$, or $180 \mathrm{~min}$ before each was naturally cooled in the crucible. The grain refinement experiment was carried out in a well-type resistance furnace. A certain amount of commercially pure aluminum was melted in an $\mathrm{Al}_{2} \mathrm{O}_{3}$ crucible and when the temperature of the aluminum melt rose to $730 \pm 5^{\circ} \mathrm{C}$, and, after refining, stirring, and skimming, we added the Al-5Ti-0.62C master alloy with a mass fraction of $0.4 \%$. After the Al-5Ti-0.62C master alloy was added into the aluminum melt, it was sufficiently stirred so as to allow it to melt and mix well. It was held for 20 or $120 \mathrm{~min}$, before it was naturally cooled in the crucible. In order to investigate the role of melt agitation on precipitation, the refined sample which was made through the above methods and preserved for 120 min was sufficiently stirred before being allowed to cool naturally.

The cooled and solidified sample was removed from the crucible, and the ingot was sawed longitudinally exactly in the center. All of the samples were sand papered, polished, and etched with a reagent $\left(60 \% \mathrm{HCl}+30 \% \mathrm{HNO}_{3}+5 \%\right.$ $\mathrm{HF}+5 \% \mathrm{H}_{2} \mathrm{O}$, volume fractions). Finally, the analysis was conducted on the phase composition, microstructure morphology, and components of the alloy with a RigakuD/maxA X-ray diffraction meter (XRD, PW 3040/60, PANalytical, Rotterdam, Holland), large optical microscope (OM, MEF3, Leica Inc, Austria), and a JSM-7500 scanning electron microscope (SEM, SSX-550 fitted with EDS equipment, Shimadzu Corporation, Kyoto, Japan).

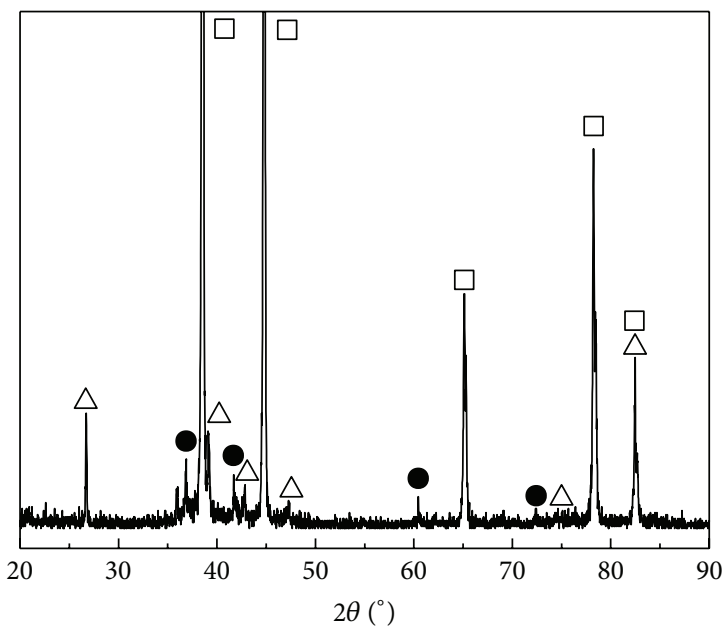

$\square \mathrm{Al}$
$\triangle \mathrm{TiC}^{\square}$
$\mathrm{TiAl}_{3}$

FIGURE 1: XRD pattern of Al-5Ti-0.62C master alloy.

\section{Results and Discussion}

3.1. Microstructures of Al-5Ti-0.62C Alloys. Figure 1 shows the XRD (X-ray diffraction) pattern of the Al-5Ti-0.62C alloys. The Al-5Ti-0.62C alloy is composed of $\mathrm{Al}, \mathrm{TiAl}_{3}$, and TiC. Figure 2(a) shows the OM photograph of the Al-5Ti$0.62 \mathrm{C}$ alloy. We observed on the Al substrate of the Al$5 \mathrm{Ti}-0.62 \mathrm{C}$ alloy a large number of strip-like or lump-like substances that were uniformly distributed with a size of roughly $20-55 \mu \mathrm{m}$ in length and $8-12 \mu \mathrm{m}$ in width, as well as small black particles. Figures 2(b) and 2(c) show the SEM image of the strip-like substances and that of the small black particles. Table 2 shows the analysis results of the energy spectrum of the chemical composition of point A in lumplike substances and of point B in small particles in Figure 2. From Table 2, we can see that at point A in the strip-like substances, the molar mass fraction of elemental Al was $69.72 \%$, the molar mass fraction of elemental Ti was $21.85 \%$, and the molar mass ratio between elemental $\mathrm{Al}$ and elemental $\mathrm{Ti}$ was 3.19. At point $\mathrm{B}$ in the small particles, the molar mass fraction of elemental C was $27.98 \%$, the molar mass fraction of elemental $\mathrm{Ti}$ was $25.52 \%$, and the molar mass ratio between elemental $\mathrm{C}$ and elemental Ti was 1.1. According to the analysis results from the XRD pattern of the Al-5Ti-0.62C alloy, we could see that the strip-like substances in Figure 2(b) were $\mathrm{TiAl}_{3}$, and the small black particles in Figure 2(c) were TiC. From the above analysis, we knew that in the Al-5Ti$0.62 \mathrm{C}$ alloys used in the experiment a large number of striplike or lump-like $\mathrm{TiAl}_{3}$ and $\mathrm{TiC}$ particles were found and distributed in a dispersed and uniform manner.

3.2. Study of the Precipitation Phenomenon of the Titanium Compound. Figure 3 shows the macrographs of the longitudinal section of the samples obtained after remelting the Al-5Ti-0.62C master alloy over different heat-treatment 


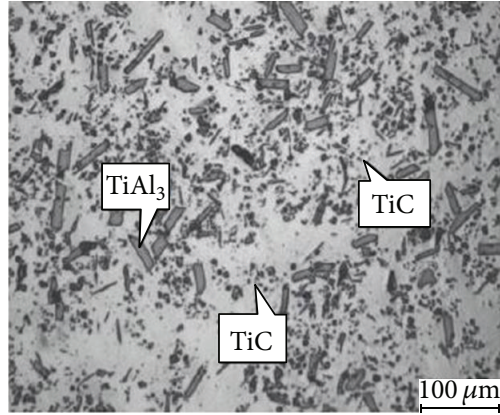

(a)

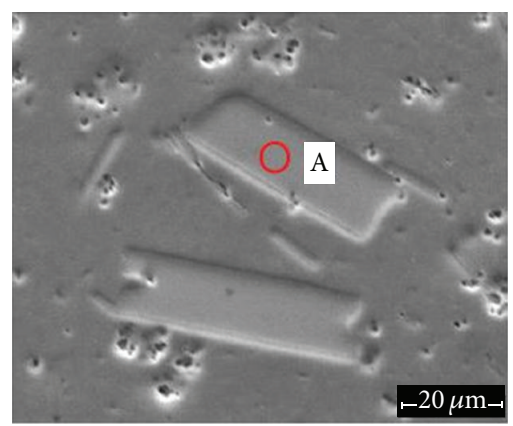

(b)

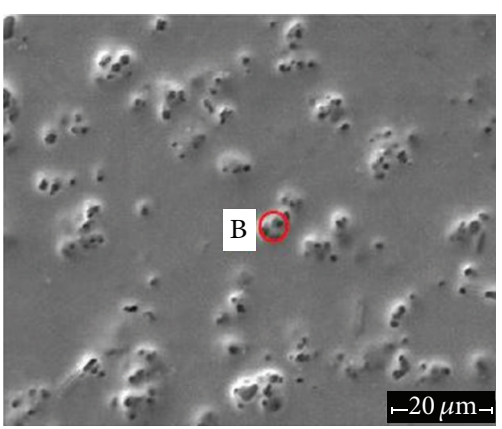

(c)

FIGURE 2: Microstructures of the Al-5Ti-0.62C alloy: (a) optical microscopy (OM) image; (b) scanning electron microscopy (SEM) image of $\mathrm{TiAl}_{3}$; and (c) SEM image of TiC.

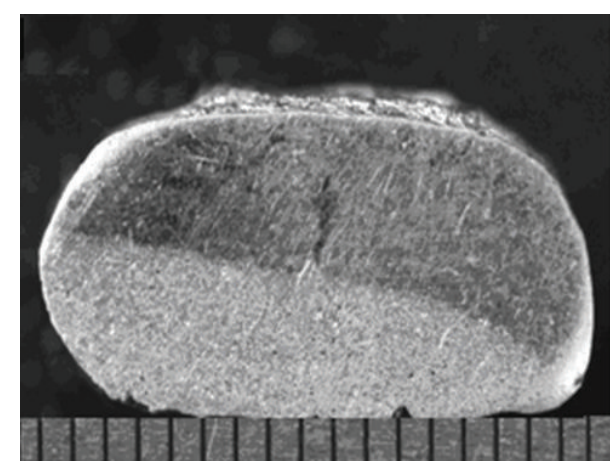

(a)

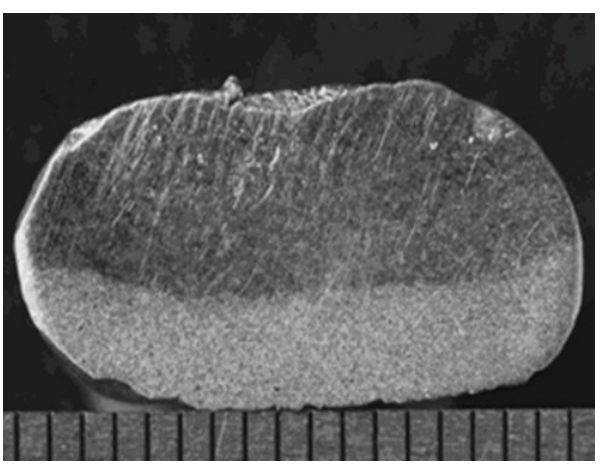

(c)

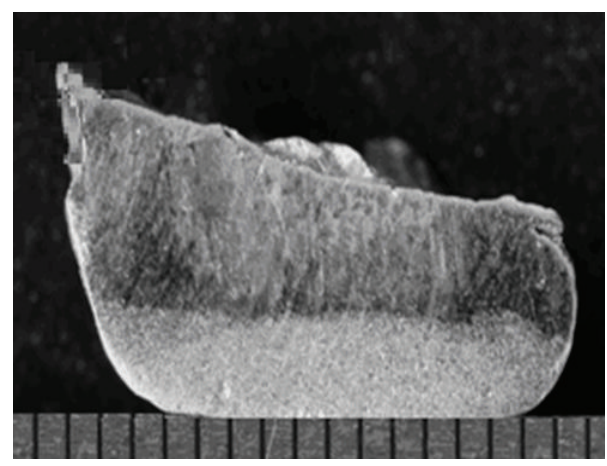

(b)

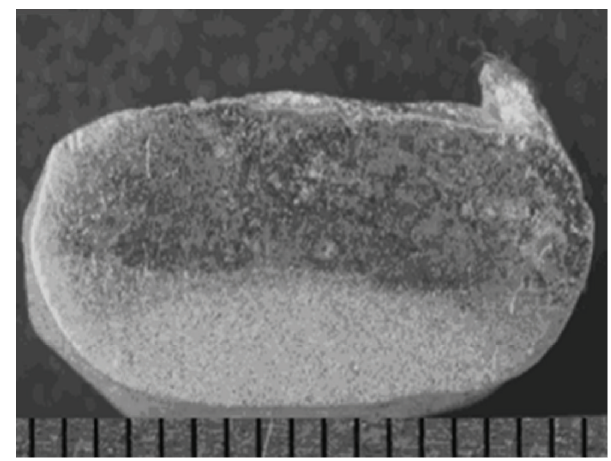

(d)

FIGURE 3: Macrographs of the longitudinal section of the samples obtained after remelting the Al-5Ti-0.62C master alloy with different heattreatment times: (a) $30 \mathrm{~min}$; (b) $60 \mathrm{~min}$; (c) $120 \mathrm{~min}$; or (d) $180 \mathrm{~min}$.

periods. As can be seen from Figure 3, after different heattreatment periods of remelting, an apparent stratification phenomenon was observed in all of the macroscopic samples. Figure 4 shows the microstructure of the remelted Al-5Ti$0.62 \mathrm{C}$ master alloy with a heat-treatment time of $180 \mathrm{~min}$. As can be seen from Figure 4(a), after remelting and heat preservation for $180 \mathrm{~min}$, the microstructure of the top portion of the sample shown in Figure 3(d) shows almost no particles. However, a severe segregation phenomenon appeared at the stratification portion (Figure $4(\mathrm{~b})$ ), and there appeared at the lower portion of the stratification a large number of sediment layers primarily composed of aggregated particles and strip-like or lump-like substances (Figure 4(c)). Table 3 depicts the EDS results of the chemical compositions of point A of strip-like substances in the deposited layer and of point B of black aggregated particles at the grain boundary. Table 3 illustrates that at point A of the strip-like substances, the molar mass fraction of elemental Al was $77.38 \%$, the molar mass fraction of elemental $\mathrm{Ti}$ was $22.62 \%$, and the molar mass ratio between elemental $\mathrm{Al}$ and elemental $\mathrm{Ti}$ was 3.4, while, at point B of the aggregated particles, the molar mass fraction of elemental C was $25.29 \%$, the molar mass fraction of elemental $\mathrm{Ti}$ was $22.31 \%$, and the molar mass ratio between elemental $\mathrm{C}$ and elemental $\mathrm{Ti}$ was 1.1; this confirmed 


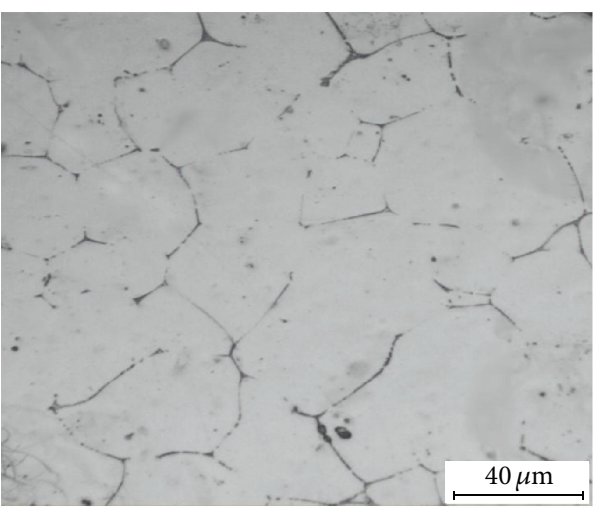

(a)

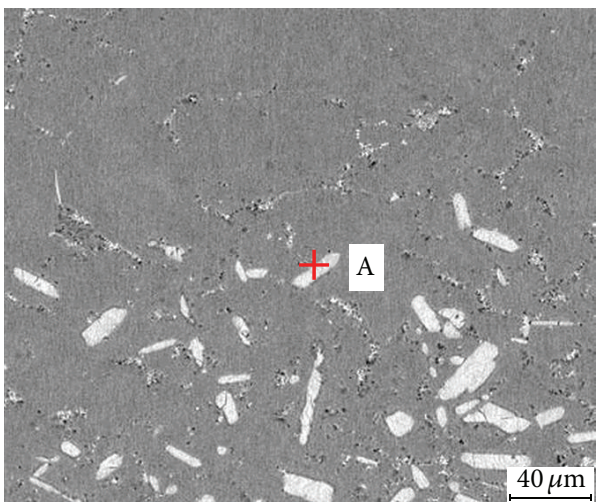

(c)

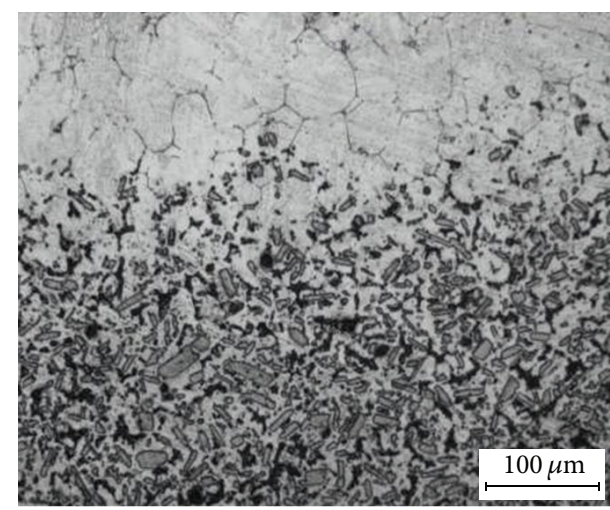

(b)

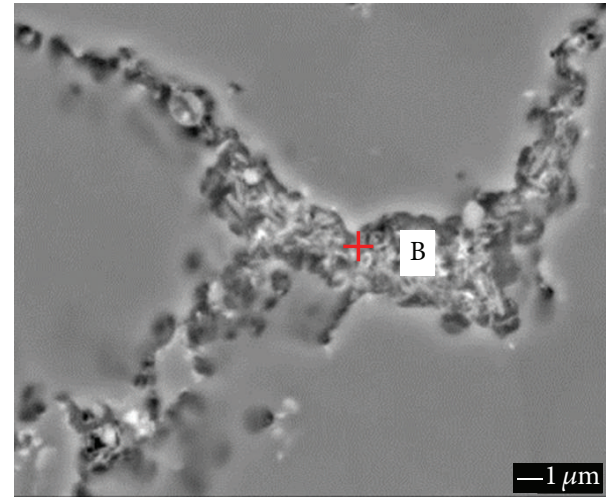

(d)

FIGURE 4: Microstructure of the remelted Al-5Ti-0.62C master alloy at a heat-treatment time of 180 min: (a) OM image at the top portion; (b) OM image at the stratification portion; (c) SEM image at the stratification portion; and (d) SEM image of aggregates at the grain boundaries of $\alpha$-Al.

TABLE 3: EDS composition analysis of point $A$ and point $B$ in Figure 4.

\begin{tabular}{lccc}
\hline Point number & $x(\mathrm{Al}) / \%$ & $x(\mathrm{Ti}) / \%$ & $x(\mathrm{C}) / \%$ \\
\hline A & 77.38 & 22.62 & - \\
B & 52.40 & 22.31 & 25.29 \\
\hline
\end{tabular}

that the strip-like substances in the precipitation layer were $\mathrm{TiAl}_{3}$, and the aggregated particles were TiC. Figure 5 depicts the microstructures of the precipitation layers at the bottom of the samples of the remelted Al-5Ti-0.62C master alloy after different heat-treatment times. As can be seen, after different times of remelting the Al-5Ti-0.62C master alloy, the precipitates at the bottom of the samples were still mainly aggregated particles and strip-like or lump-like substances. According to the SEM image (Figure 6) and EDS results of the chemical compositions of the black aggregated particles at the grain boundary (Table 4) and the precipitation layers at the bottom of the sample of the remelted Al-5Ti-0.62C master alloy after a heat-treatment time of $180 \mathrm{~min}$, we observed that precipitates at the bottom of the sample were still $\mathrm{TiAl}_{3}$ and TiC.

Figure 7 shows the precipitates at the bottom of the samples after different heat-treatment times during the
TABLE 4: EDS composition analysis of point $\mathrm{A}$ and point $\mathrm{B}$ in Figure 6.

\begin{tabular}{lccc}
\hline Point number & $x(\mathrm{Al}) / \%$ & $x(\mathrm{Ti}) / \%$ & $x(\mathrm{C}) / \%$ \\
\hline A & 75.64 & 24.36 & - \\
B & 52.20 & 22.79 & 25.01 \\
\hline
\end{tabular}

refinement of commercially pure aluminum by the Al-5Ti0.62C master alloy. It can be seen from Figure $7(\mathrm{a})$ that after a heat-treatment time of $20 \mathrm{~min}$, there was a small amount of precipitate at the bottom of the sample; but when the heat-treatment time was $120 \mathrm{~min}$, a large amount of precipitate appeared at the bottom of the sample. As can be seen from the mapping analysis results of the precipitates at the bottom of the samples refined with the Al-5Ti-0.62C master alloy after $120 \mathrm{~min}$ of heat treatment (Figure 8), the particles that aggregated at the grain boundary were rich in the elements $\mathrm{Ti}$ and $\mathrm{C}$. Figure 9 shows the line scanning and EDS spectrum of aggregates at the grain boundary of $\alpha-\mathrm{Al}$ in Figure 8(a). According to the line scanning (Figure 9(a)) and point analysis (Figure 9(b)) results of the particles at the grain boundary, we can observe that the precipitates at the bottom of the sample in Figure 8 (a) were mainly the $\mathrm{TiC}$ particles added to the Al-5Ti-0.62C master alloy; that is, $\mathrm{TiC}$ 


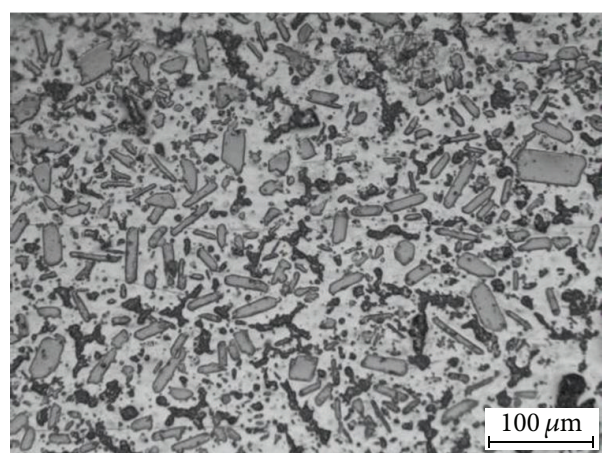

(a)

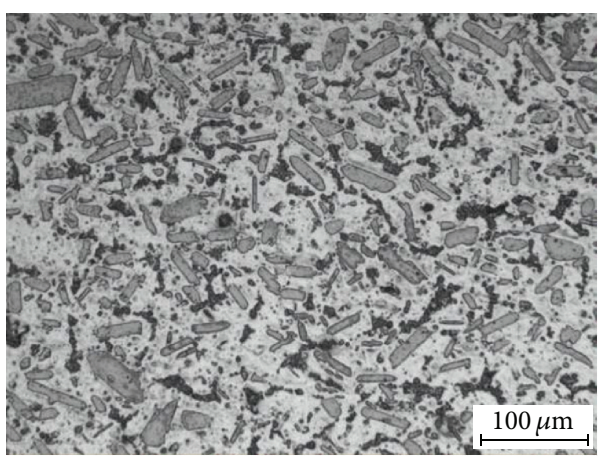

(c)

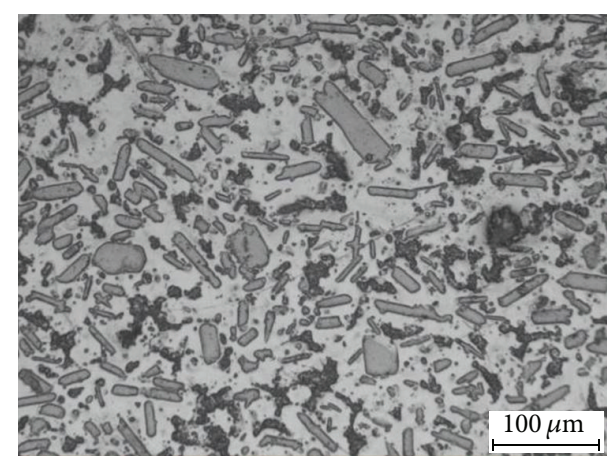

(b)

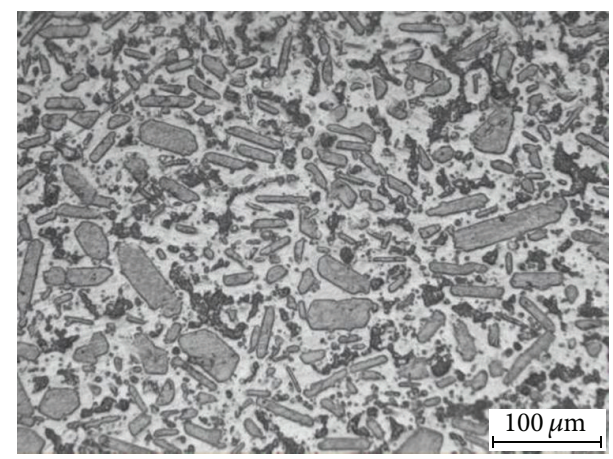

(d)

FIGURE 5: Microstructures of the precipitation layers at the bottom of the samples of remelted Al-5Ti-0.62C master alloy after different heattreatment times: (a) $30 \mathrm{~min}$; (b) $60 \mathrm{~min}$; (c) $120 \mathrm{~min}$; or (d) $180 \mathrm{~min}$.

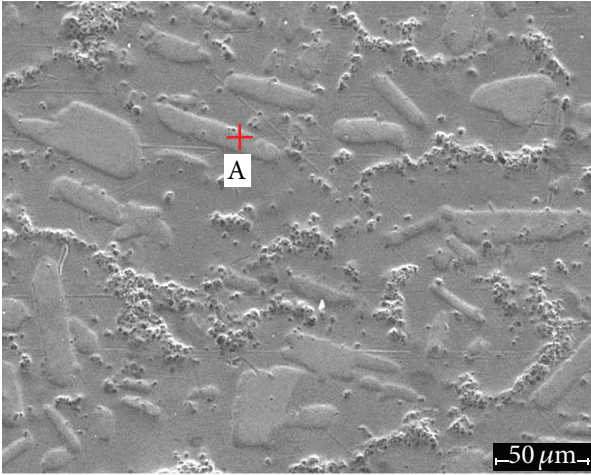

(a)

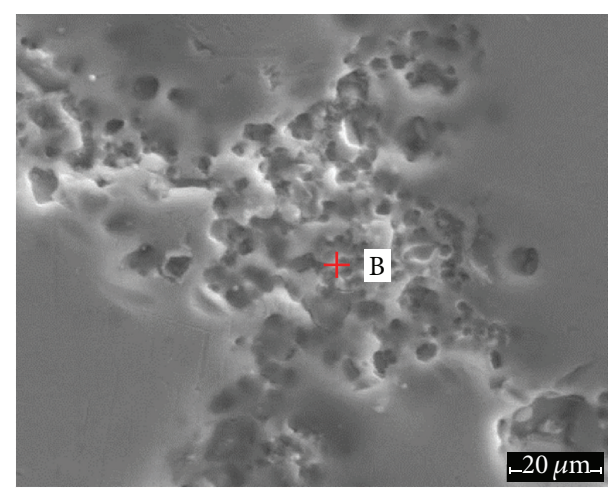

(b)

FIGURE 6: SEM images of the precipitation layers at the bottom of the samples of remelted Al-5Ti-0.62C master alloy after 180 min of heat treatment: (a) $180 \mathrm{~min}$, SEM image; (b) SEM image of aggregated particles at the $\alpha$-Al grain boundary.

precipitation occurred. Small lump-like or strip-like $\mathrm{TiAl}_{3}$ were not found to exist in the precipitates of the refinement sample, which was due to the fact that in the case of less added alloy; the $\mathrm{TiAl}_{3}$ added to the aluminum melt was melted in a short period of time before it precipitated to the bottom of the sample and became the Ti solute [18] in the aluminum melt.

3.3. Discussion of the Refinement Fading Mechanism of the Al5Ti-0.62C Alloy. From the above analysis, we observed that the Al-5Ti-0.62C master alloy melt severely segregated during the process of heat treatment and that this segregation was caused by the sinking of $\mathrm{TiAl}_{3}$ and $\mathrm{TiC}$ in liquid aluminum as affected by gravity. Dissolution occurred when $\mathrm{TiAl}_{3}$ was in the molten aluminum for a long period of time and preferential growth occurred during the solidification process after complete dissolution; that is, the vertical growth rate of the plane $\{111\}$ whose crystal atoms of the body-centered cube were arranged most loosely was the fastest, while the growth rate of the closely packed plane $\{110\}$ was the slowest [19]. During the sinking process, because of the poor wettability between $\mathrm{TiC}$ particles and the aluminum melt, there existed a very high interfacial energy at the boundary 


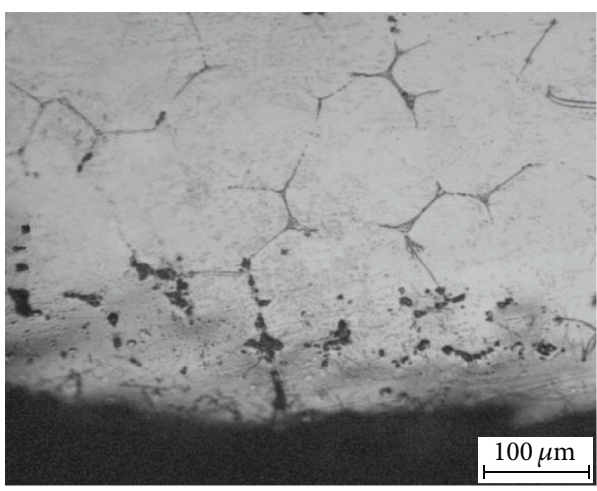

(a)

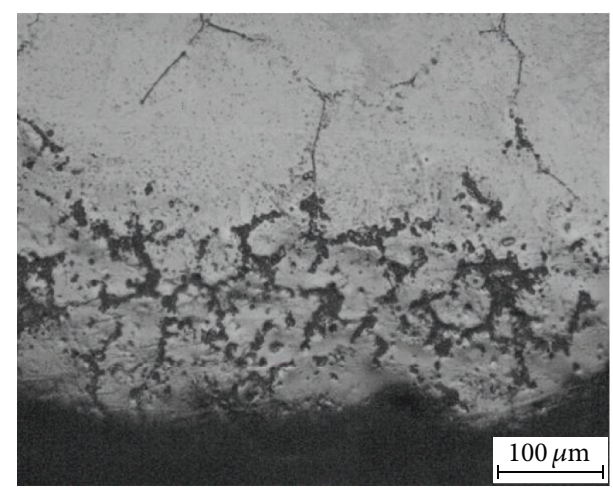

(b)

FIGURE 7: Precipitates at the bottom of solidified Al samples refined with Al-5Ti-0.62C master alloys at different heat-treatment times: (a) $20 \mathrm{~min}$; (b) $120 \mathrm{~min}$.

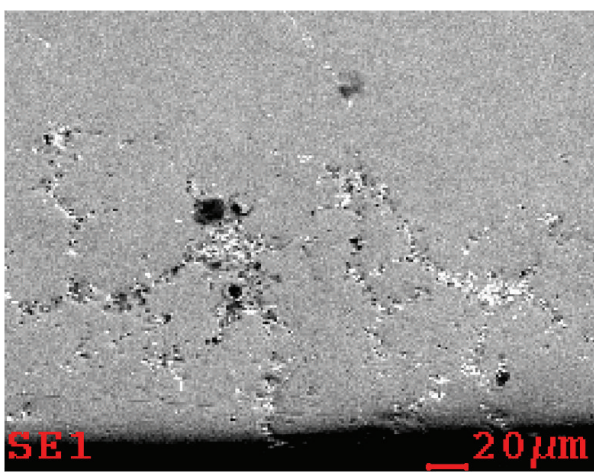

(a)

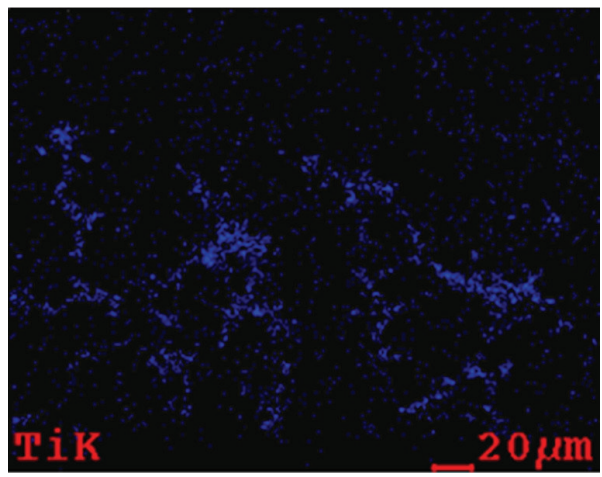

(c)

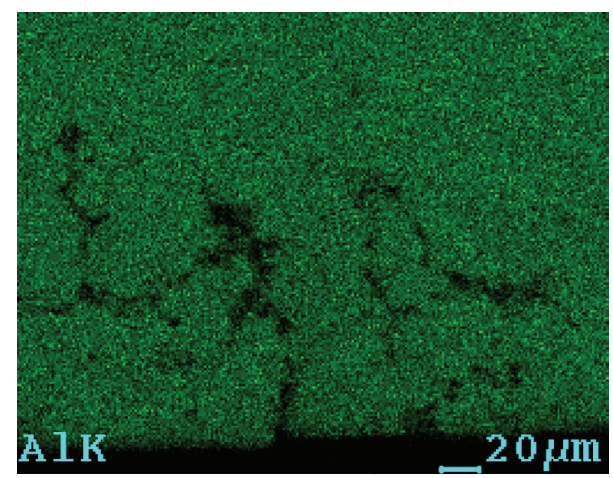

(b)

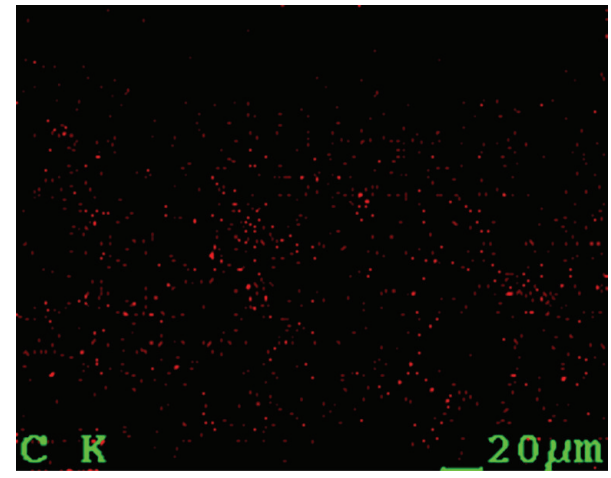

(d)

FIGURE 8: SEM image and mapping analysis at the bottom of the samples refined with the Al-5Ti-0.62C master alloy after 120 min of heat treatment: (a) 120 min, SEM image; (b) elemental Al element; (c) elemental Ti; (d) elemental C.

between $\mathrm{TiC}$ particles and liquid aluminum. Excluded by the liquid aluminum, TiC particles aggregated, such that in some areas there was a high density of TiC particles that may even have adhered to one another. According to Stokes' formula [20], the sinking speed in the melt particles whose radius is smaller than $0.1 \mathrm{~cm}$ is calculated by the following formula: $v=2 r^{2}(\rho 1-\rho 2) / 9 \mu$, where $v$ is the descending speed of the particles, $r$ is the radius of the particles, $\rho 1$ is the density of the particles, $\rho 2$ is the density of the aluminum liquid, and $\mu$ is the viscosity of the molten aluminum. It can be seen that the sinking speed of the particles mainly depends on the volume of the particles, the difference between the density of the particles and that of the molten aluminum, and the viscosity of the aluminum fluid. Therefore, when the $\mathrm{TiC}$ particles gather into larger particle clusters, the precipitation of $\mathrm{TiC}$ will be further accelerated. Due to the structural heredity of the Al-Ti-C master alloy [21], the precipitation phenomena possess aspects in the refinement process similar to those of the remelting process, such that both $\mathrm{TiAl}_{3}$ and $\mathrm{TiC}$ particles introduced during the refinement process aggregate 


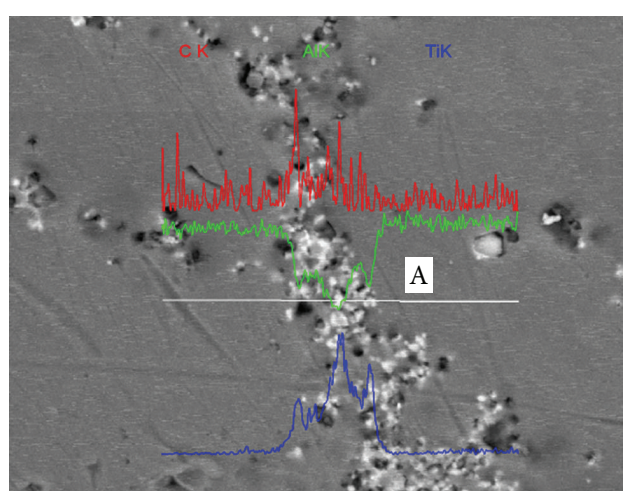

(a)

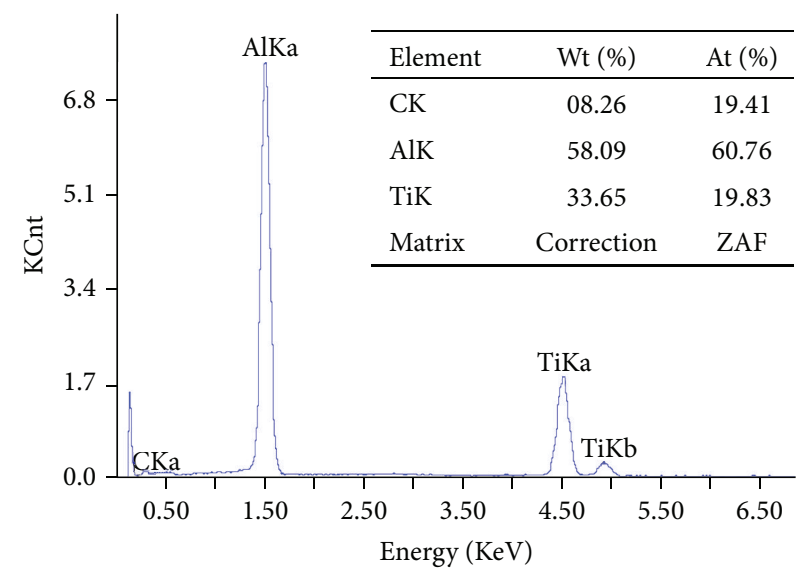

(b)

FIGURE 9: Line scanning and EDS spectrum of aggregates at the grain boundary of $\alpha$-Al in Figure 8(a): (a) line scanning; (b) EDS spectrum of point $\mathrm{A}$.

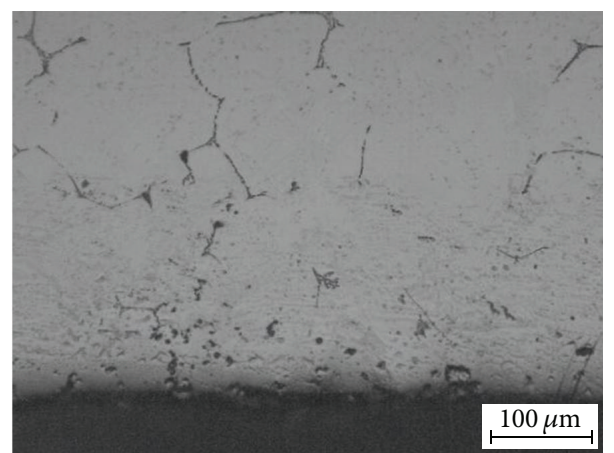

Figure 10: Micrograph at the bottom of the sample refined with Al-5Ti-0.62C master alloys at 120 min of heat treatment and after stirring.

and precipitate, and they only differ in their length of time. When a very small amount of Al-5Ti-0.62C master alloy is added into the molten aluminum, most $\mathrm{TiAl}_{3}$ will dissolve into the molten aluminum and release $\mathrm{Ti}$ atoms in the process of sinking. As Ti manifests poor activity between $\mathrm{TiC}$ and the aluminum melt [18], these $\mathrm{Ti}$ atoms segregate around the $\mathrm{TiC}$ particles, forming the "Ti-rich zone on the $\mathrm{TiC} / \alpha-\mathrm{Al}$ interface" $[18,22]$, and become the heterogeneous nucleation core of $\alpha$ (A1) when the aluminum melt solidifies. With the extension of the heat-treatment time for the aluminum melt, a large number of $\mathrm{TiC}$ particles deposit at the bottom of the sample; this allows during solidification of the melt only a small amount of residual $\mathrm{TiC}$ in the middle and upper portion of the sample to form the "Ti-rich zone on the $\mathrm{TiC} / \alpha-\mathrm{Al}$ interface" and become nucleation particles. This then causes the phenomenon of refinement fading.

In order to study the role of melt mixing in the process of grain refinement and its effects on $\mathrm{TiC}$ precipitation, we allowed sufficient stirring before the natural cooling of the refinement sample after a heat treatment of $120 \mathrm{~min}$. As can be seen from Figure 10, there were almost no precipitates at the bottom of the refinement sample, which had been stirred sufficiently and heat preserved for $120 \mathrm{~min}$. Figure 11 shows the macrographs obtained without stirring and with sufficient stirring before the cooling of the refinement samples after heat treatment of $120 \mathrm{~min}$. As can be seen from Figure 11, significant differences in the grain size exist between the top and bottom of the unstirred sample: the grains at the top of the sample are large, while those at the bottom are small, and the closer to the bottom, the smaller the grains (Figure 11(a)). The difference in grain size between the top and bottom of the sample after sufficient stirring prior to natural cooling was significantly reduced, with the grain size becoming substantially uniform (Figure 11(b)). This shows that stirring action can make parts of the $\mathrm{TiC}$ particles redistribute in a dispersed way so as to restore the refinement effect.

\section{Conclusions}

(i) The Al-5Ti-0.62C master alloy exhibits an obvious precipitation phenomenon of titanium compounds in the aluminum melt. In the precipitates of the remelted Al-5Ti-0.62C master alloy, there were both TiC compounds and $\mathrm{TiAl}_{3}$ compounds; in the refinement sample of commercially pure aluminum, the precipitates were mainly $\mathrm{TiC}$ compounds.

(ii) The precipitation of titanium compounds in the aluminum melt is the main cause of the decline in 


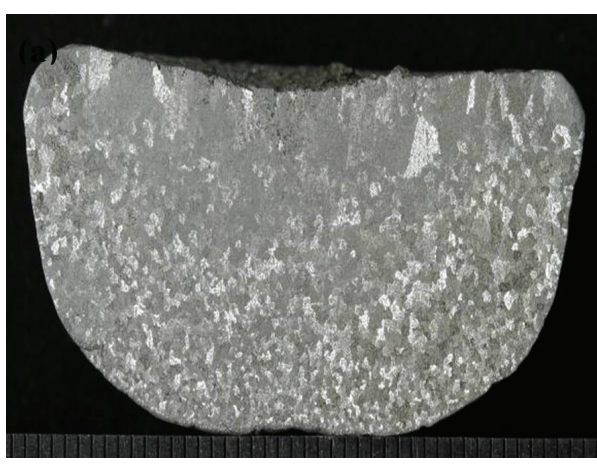

(a)

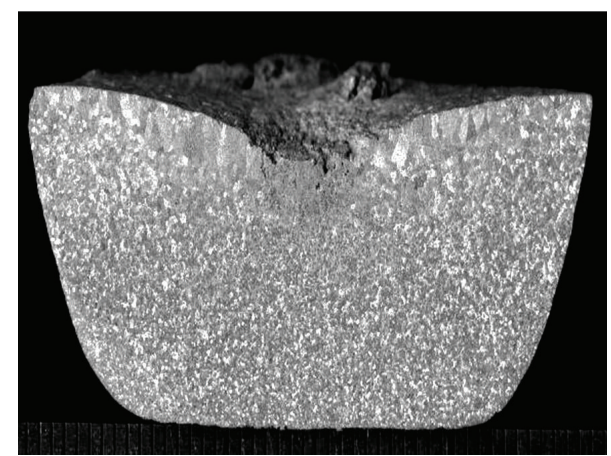

(b)

FIGURE 11: Macrographs of solidified Al samples refined with Al-5Ti-0.62C master alloys at 120 min of heat treatment: (a) without stirring; (b) with sufficient stirring.

the refinement effect of the $\mathrm{Al}-5 \mathrm{Ti}-0.62 \mathrm{C}$ master alloy, and sufficient stirring of the melt can thus allow $\mathrm{TiC}$ particles to redistribute in a dispersed way so as to restore the refinement effect.

\section{Conflict of Interests}

The authors declare that they have no conflict of interests.

\section{Acknowledgments}

This research was financially supported by the National Natural Science Foundation of China (no. 50965012). The authors would like to acknowledge the financial support of the Natural Science Foundation of Gansu Province in China (Grants nos. 1308RJYA088, 1308RJZA291, and 145RJYA295).

\section{References}

[1] D. G. McCartney, "Grain refining of aluminium and its alloys using inoculants," International Materials Reviews, vol. 34, no. 5, pp. 247-260, 1989.

[2] B. S. Murty, S. A. Kori, and M. Chakraborty, "Grain refinement of aluminium and its alloys by heterogeneous nucleation and alloying," International Materials Reviews, vol. 47, no. 1, pp. 329, 2002.

[3] G. P. Jones and J. Pearson, "Factors affecting the grainrefinement of aluminum using titanium and boron additives," Metallurgical Transactions B, vol. 7, no. 2, pp. 223-234, 1976.

[4] A. M. Bunn, P. Schumacher, M. A. Kearns, C. B. Boothroyd, and A. L. Greer, "Grain refinement by Al-Ti-B alloys in aluminium melts: a study of the mechanisms of poisoning by zirconium," Materials Science and Technology, vol. 15, no. 10, pp. 1115-1123, 1999.

[5] H. Li, T. Sritharan, and H. P. Seow, "Grain refinement of DIN226 alloy at high titanium and boron inoculation levels," Scripta Materialia, vol. 35, no. 7, pp. 869-872, 1996.

[6] Z.S. Gao, "Recent development of Al-Ti-C grain refining master alloys," Light Alloys Pressing Technology, vol. 26, no. 10, pp. 5-11, 1998.
[7] J.-G. Li, M. Huang, M. Ma et al., "Performance comparison of AlTiC and AlTiB master alloys in grain refinement of commercial and high purity aluminum," Transactions of Nonferrous Metals Society of China, vol. 16, no. 2, pp. 242-253, 2006.

[8] X. F. Liu, Z. Q. Wang, Z. G. Zhang, and X. F. Bian, “The relationship between microstructures and refining performances of Al-Ti-C master alloys,' Materials Science and Engineering A, vol. 332, no. 1-2, pp. 70-74, 2002.

[9] Z.-Q. Wang, X.-F. Liu, Y.-H. Liu, J.-Y. Zhang, L.-N. Yu, and X.-F. Bian, "Structural heredity of $\mathrm{TiC}$ and its influences on refinement behaviors of AlTiC master alloy," Transactions of Nonferrous Metals Society of China, vol. 13, no. 4, pp. 790-793, 2003.

[10] Y. L. Li, J. L. Wen, and Y. B. Chen, "Al-3Ti-0.15C grain refiner prepared by SHS," Transactions of Nonferrous Metals Society of China, vol. 14, pp. 179-183, 2004.

[11] A. Banerji and W. Reif, "Development of Al-Ti-C Grain Refiners containing TiC," Metallurgical Transactions A, vol. 17, no. 12 , pp. 2127-2137, 1986.

[12] N. Iqbal, N. H. van Dijk, S. E. Offerman et al., "In situ investigation of the crystallization kinetics and the mechanism of grain refinement in aluminum alloys," Materials Science and Engineering A, vol. 416, no. 1-2, pp. 18-32, 2006.

[13] Z. B. Xiao, Y. L. Deng, and J. G. Tang, "Poisoning mechanism of $\mathrm{Zr}$ on grain refiner of $\mathrm{Al}-\mathrm{Ti}-\mathrm{C}$ and $\mathrm{Al}-\mathrm{Ti}-\mathrm{B}$," Transactions of Nonferrous Metals Society of China, vol. 22, pp. 371-378, 2012.

[14] S. J. Wang, Study on the "Poisoning" Phenomena and the New Refining Technique for Zr-Bearing Aluminum Alloys, Shandong University, Jinan, China, 2009.

[15] W. J. Zhao, W. W. Ding, and T. D. Xia, "Research status and development trend of preparation of Al-Ti-C master alloy," Foundry Technology, vol. 29, pp. 1559-1562, 2008.

[16] W. W. Ding, T. D. Xia, W. J. Zhao, and Y. T. Xu, "Effect of Al-5Ti$\mathrm{C}$ master alloy on the microstructure and mechanical properties of hypereutectic Al-20\%Si alloy," Materials, vol. 7, no. 2, pp. 1188-1200, 2014.

[17] W.-W. Ding, T.-D. Xia, W.-J. Zhao, and Y.-F. Hou, "Refining performances of $\mathrm{TiC}$ and $\mathrm{TiAl}_{3}$ phases in master alloys on pure aluminum," Chinese Journal of Nonferrous Metals, vol. 19, no. 6, pp. 1025-1031, 2009.

[18] L. N. Yu and X. F. Liu, "Ti transition zone on the interface between $\mathrm{TiC}$ and aluminum melt and its influence on melt 
viscosity," Journal of Materials Processing Technology, vol. 182, no. 1-3, pp. 519-524, 2007.

[19] Z. X. Zhu, Engineering Materials, Tsinghua University Press, Beijing, China, 2001.

[20] D. H. Wu, J. L. Ren, and S. C. Chen, Modern Materials Processing, Tsinghua University Press, Beijing, China, 1997.

[21] X. F. Bian, X. F. Liu, and J. J. Ma, Casting Metal Genetics, Shandong Science and Technology Press, Jinan, China, 1999.

[22] T. D. Xia, W. W. Ding, and W. J. Zhao, "Effect of distribution of $\mathrm{TiC}$ in aluminum matrix in the presence of solute $\mathrm{TiAl}_{3}$ and nucleation mechanism of Al-Ti-C," Transactions of Nonferrous Metals Society of China, vol. 19, pp. 1948-1955, 2009. 

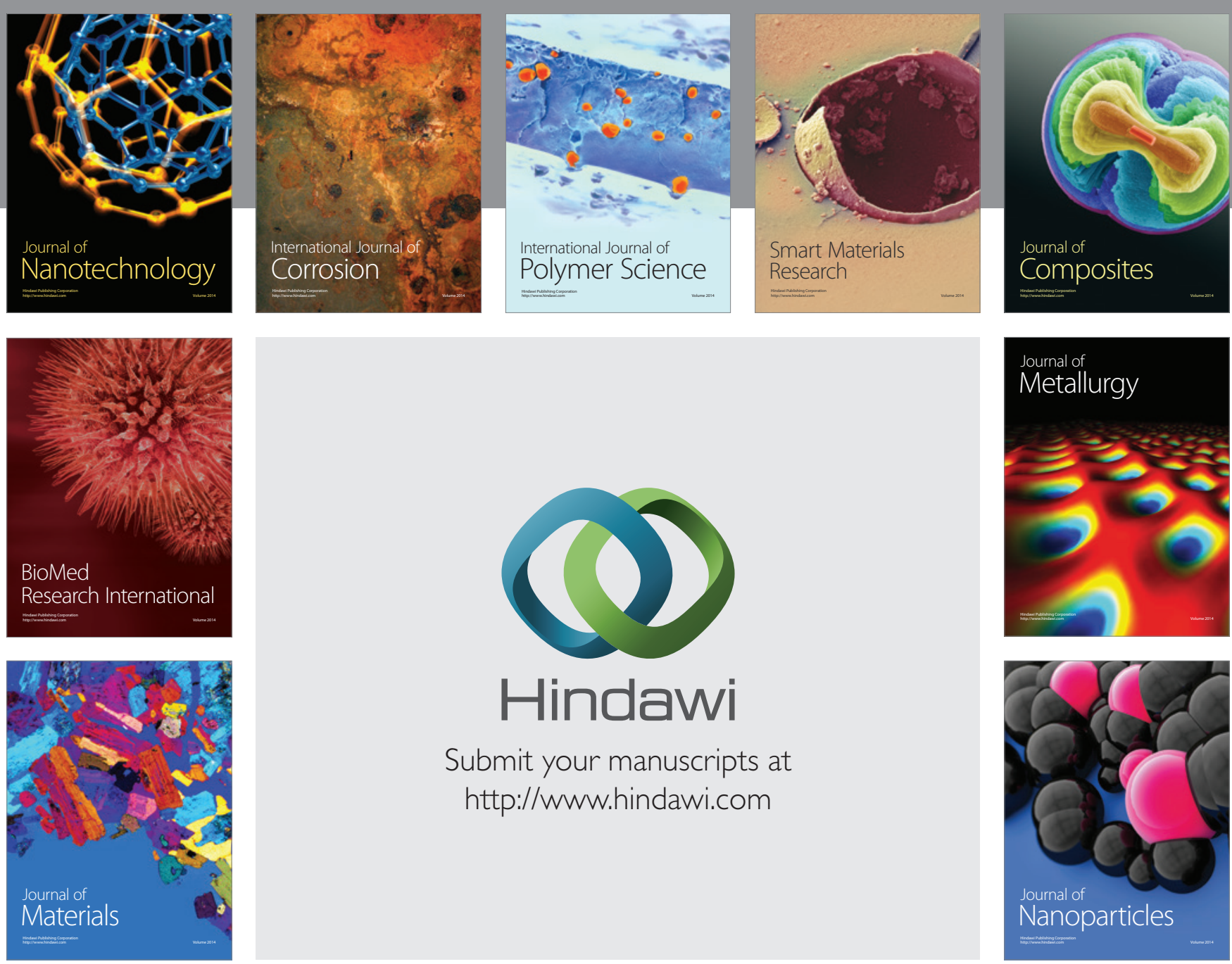

Submit your manuscripts at http://www.hindawi.com
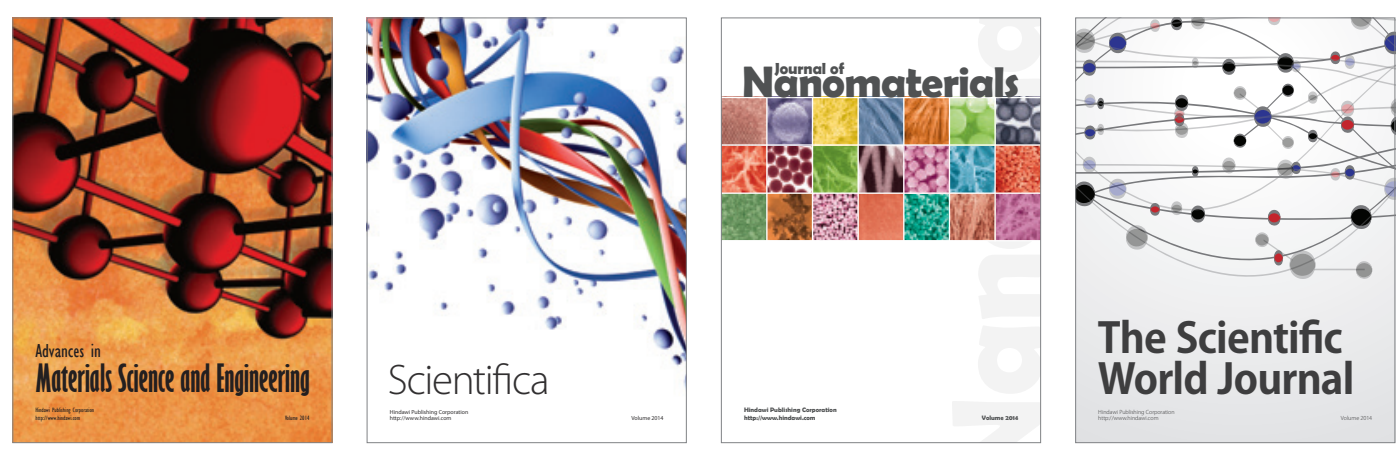

\section{The Scientific World Journal}
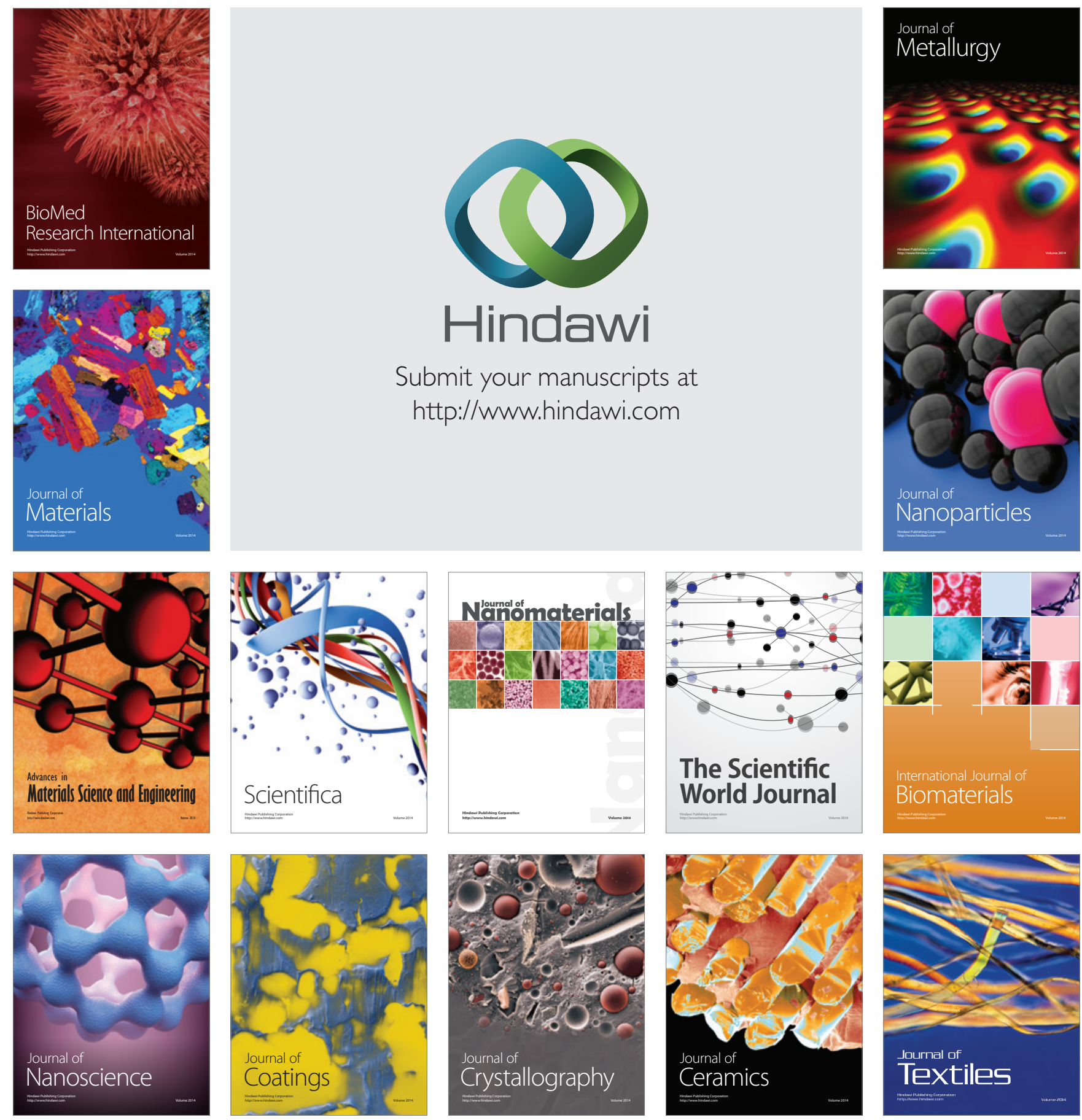